OPEN ACCESS

Edited by:

Hui Yao,

Beijing University of Technology,

China

Reviewed by:

Han-Cheng Dan,

Central South University, China

Liang He,

Chongqing Jiaotong University, China

*Correspondence:

Dongya Ren

dongyaren@switu.edu.cn

Specialty section: This article was submitted to

Structural Materials,

a section of the journa

Frontiers in Materials

Received: 21 August 2020 Accepted: 24 November 2020

Published: 14 January 2021

Citation:

Li L, Huang Y, Shao $Z$ and Ren D (2021) An Experimental Investigation

on the Repairing Performance and

Fatigue Life of Asphalt Pavement

Potholes With an Inclined

Interface Joint.

Front. Mater. 7:597523.

doi: 10.3389/fmats.2020.597523

\section{An Experimental Investigation on the Repairing Performance and Fatigue Life of Asphalt Pavement Potholes With an Inclined Interface Joint}

\author{
Linyu $\mathrm{Li}^{1,2}$, Yangquan Huang ${ }^{1,2}$, Zhutao Shao ${ }^{1,2}$ and Dongya Ren ${ }^{1,2 *}$ \\ ${ }^{1}$ School of Civil Engineering, Southwest Jiaotong University, Chengdu, China, ${ }^{2}$ Key Laboratory of Highway Engineering of \\ Sichuan Province, Southwest Jiaotong University, Chengdu, China
}

A pothole is a typical structural damage of asphalt pavements that significantly influence the life of asphalt pavements and driving safety. The durability of the existing pit repair methods is generally low. The existing studies in the context of pothole repair mainly focus on the selection and the amount of tack coat materials, nonetheless, very limited studies emphasize the effect of the joint interface shape. This study aims to investigate the influence of the interface joint shape on the service life of pothole repair by experimental testing. The strength and fatigue behavior of the joints were studied and the effectiveness of pothole repairs was evaluated under various conditions, including four temperature levels $\left(5,10,15\right.$ and $\left.25^{\circ} \mathrm{C}\right)$, four strain levels $(750 \mu \varepsilon, 1,000 \mu \varepsilon, 1,250 \mu \varepsilon$, and 1,500 $\mu \varepsilon)$ and three loading frequencies $(2,5$, and $10 \mathrm{~Hz})$. The optimal interface joint shape was obtained by orthogonal tests. The results indicated that the bond strength and fatigue life of the high viscoelastic emulsified asphalt with an area density of $0.6 \mathrm{~kg} / \mathrm{m}^{2}$ in the form of a $30^{\circ}$ inclination joint was 473 and 80 times higher than those of traditional pothole repair (i.e., vertical joint form and no tack coat), respectively. Finally, a prediction model was proposed for the interface joint fatigue life considering external parameters through multiple regression analyses. This prediction model can provide a reference for the further study of asphalt pavement pothole repair.

Keywords: asphalt pavement, pothole patching, inclined interface joint, bond strength, fatigue life

\section{INTRODUCTION}

Potholes are a kind of damage taking place on the surface of pavement in which the material fractures in a relatively short time period cause a steep depression (Nicholls et al., 2014). Potholes are a common form of distress on highway asphalt pavements, due to not repairing the pavement distresses at the initial stage of their development (Ghosh et al., 2018). Moisture and traffic load are considered as the two major causes of potholes (Kang and Sun, 2003; Little and Jones Iv, 2003; Lee et al., 2017). However, the causes are often complex and many factors may influence the performance of the repaired potholes, including the traffic load, the time interval for scheduled reconstruction, personnel, equipment, availability of materials and the tolerance of the traveling public (Wilson and Romine, 2001). Moreover, the formation of potholes can be dependent on the type of asphalt pavement surfacing and the materials used. When asphalt mixture is used on the road surface, potholes are developed because of cracking of asphalt surfacing, water penetration into the asphalt, 
and traffic loading, while for the thin asphalt-surfacing seals, loss of surfacing, cracking, poor repairs, and poor adhesion between the base and seal coat may lead to pothole occurrence (PaigeGreen et al., 2010).

The pavement reconstruction can eliminate the asphalt pavement pothole, but the cost is high. It is found that the service life of asphalt pavement with potholes can be extended to $5-10$ years by conducting some low-cost treatment of potholes (Galehouse, 1998). Therefore, pothole repairing is one of the most common maintenance services carried out by highway agencies, especially in the regions with cold winters and hot and wet summers (Dong et al., 2014b). Pothole patching is usually employed either as an emergency repair under severe conditions, or as the regular maintenance scheduled service for the warmer and drier periods. Therefore, more attention is attracted to the patching materials and technology (Wang, 2011; Li, 2016). In the early 90s, the strategic highway research program (SHRP) provided a manual to describe the materials and procedures that can be used for the repair of potholes. Afterward, by conducting five years of further research on pothole repair, this manual was updated by the Federal Highway Administration's (FHWA) under Long Term Pavement Performance (LTPP) program (Wilson and Romine, 2001).

Several properties are usually considered when repairing potholes in the selection of patching material, such as workability and cohesion (Maher et al., 2001), traffic loading and environmental durability (Fragachan, 2008), bonding, freezethaw, and rutting potential (Dong et al., 2014b). For instance, Yang et al. (2015) proposed a pothole patching material for epoxy asphalt pavement on steel bridge decks. They evaluated the performance of their proposed material by conducting both experimental fatigue testing and numerical analyses. Kwon et al. (2018) carried out a study on the feasibility of using reclaimed asphalt pavement (RAP) as spray injection patching materials for pothole repair, which indicated that the mixtures containing RAP had better stability and adhesion properties compared to those which contained virgin aggregates. Li et al. (2019) introduced a high thermal conductivity asphalt pavement mastic and mixture for repairing potholes. They showed that the efficiency of the introduced mixture in terms of bond strength, rutting and cracking resistance met the standard requirements. The patching materials that are usually applied for repairing potholes include hot mixed asphalt mixture (HMA), cold mixed asphalt mixture using emulsified asphalt or cut-back asphalt, and other polymeric materials or resins. Ding et al. (2016) studied the performance of a cold mix asphalt mixture with a modified resin as a tack coat and its application in the pavement pothole repair. Moreover, they studied the strength of this cold mix mixture. However, although the cold-mix asphalt materials provide convenience in construction but they can provide limited scope of application (Yuan, 2017). Prowell and Franklin (Prowell and Franklin, 1996) evaluated different cold-mix patching materials for winter pothole repairs. HMA materials, on the other hand, can greatly improve pavement service life, but these have environmental drawbacks (Tong, 2014). It should be noted that several parameters considerably influence the testing results of pothole patches such as the testing temperatures, compaction efforts and wheel loading (Dong et al., 2014b).

There are several patching techniques employed by highway agencies for repairing potholes, including the throw-and-roll, the semi-permanent, the spray-injection, and the edge seal methods (Wilson and Romine, 2001). Dong et al. (2014a) carried out a 14-month field survey to evaluate the costeffectiveness of the two frequently used patching techniques throw-and-roll and semi-permanent with different combinations of materials and procedures. They found that the throw-and-roll patches were degraded very fast, mainly due to the severe freezing environment and insufficient compaction and curing. In addition, the semi-permanent patches demonstrated more cost-effectiveness in the long term. Their subsequent study investigated the service life of different throwand-roll pothole patches under the influence of different factors including the length, width, and depth of patches, the traffic level, the speed limit and the freeze times using statistical analyses (Dong et al., 2015). Obaidi et al. (2017) proposed a new technology as a suitable method for repairing potholes and demonstrated that with continuous renewal of pothole repair materials, the service life of the repaired surface was similar to that of a newly surfaced road. Mao (2004) studied various maintenance technologies for potholes, and analyzed the appropriate potholes repair technology combined with various climate and construction conditions. Wang et al. (2013) reported the advantages of the spray method and compared it with different pothole repair techniques. They recommended emulsified asphalt as the bonding materials in the spray process. $\mathrm{Li}$ and $\mathrm{Li}$ (2016) pointed out the disadvantages of the traditional potholes repair methods. They reported the reasons for the low service life obtained from the traditional potholes repair methods as the shortcomings of the cold joint, the weak bonding between the new and old materials at the joint, the difficult compaction of new materials, the large porosity and easy water seepage. Moreover, they proposed a permanent pothole repair method for asphalt pavement based on microwave heating.

The above-mentioned studies mainly focus on the potholes repair material and patching process. However, few researchers focused on the treatment of the interface between the old and new pavement parts in repairing asphalt pavement potholes. Shi (2006) analyzed the pothole repair methods from three perspectives of technology, material, and mechanical equipment. It was found that to ensure the performance of pothole repair, the stability of the interface joint between the new and old pavement parts should be guaranteed. It was also proved that the dry maintenance of interface joints can significantly improve the service life of the repaired potholes (Jiang, 2017). It can be seen that the joint between the old and new pavement parts is the dominant factor affecting the service life of the repaired asphalt pavement potholes. Therefore, it can be mentioned that the joint between the old and new pavement parts has a considerable influence on joint performance ( $\mathrm{Li}$ and Li, 2016; Shao et al., 2019). In previous studies, although the potholes and the interface problem have been studied, few 
TABLE 1 | The aggregate gradation of mixture (SMA-13).

$\begin{array}{lcccccccccc}\text { Sieve size }(\mathrm{mm}) & 16 & 13.2 & 9.5 & 4.75 & 2.36 & 1.18 & 0.6 & 0.3 & 0.15 & 0.075 \\ \text { Passing rate (\%) } & 100 & 95 & 62 & 27 & 20 & 19 & 16 & 13 & 12 & 10\end{array}$

studies comprehensively evaluated the performance of the joint between the new and old parts of asphalt pavement in potholes.

The purpose of this paper is to investigate the influence of the bond between the new and old pavement parts on the service performance and life of pothole repairs. The bond strength and fatigue behavior of the joints are used to evaluate the effectiveness of pothole repairs under various conditions. The orthogonal tests including the pull-out test and four-point bending fatigue test were conducted as laboratory tests and the effect of several parameters including the type and the amount of tack coat, the joint interface form, the test temperature, the load frequency and the strain level as test conditions are investigated. Moreover, the optimal interface joint form was obtained. Lastly, a prediction model of interface joint fatigue life taking into account several parameters is established through multiple regression analyses. This model can provide a reference for further study on asphalt pavement pothole repair.

\section{MATERIALS AND EXPERIMENTAL METHOD}

\section{Materials}

\section{Asphalt Mixture}

In this study, the composite beam with an interfacial joint was prepared by stone mastic asphalt (SMA-13) to simulate the pothole in asphalt layers. The gradation of SMA-13 mixture is in Table 1, and it was used as the median gradation according to the Chinese Standard of Test Methods of Bitumen and Bituminous Mixtures for Highway Engineering (Code of China, 2011). The asphalt-aggregate ratio of SMA-13 was $6.18 \%$, the coarse aggregate was basalt gravel, the fine aggregate was machine-made sand, the mineral powder was limestone alkaline, and the fiber was lignin with the dosage of $0.3 \%$. The properties of asphalt binder and asphalt mixture (SMA-13) met the requirement of the code (Code of China, 2011).

\section{Tack Coat}

Three kinds of emulsified asphalt including the ordinary emulsified asphalt (Type I), the highly viscous modified emulsified asphalt (Type II) and the resin emulsified asphalt (Type III) were considered as the tack coat. The properties of binders are listed in Table 2.

\section{Test Methods}

\section{Specimen Preparation}

As mentioned in the previous section, the beam-shaped specimens prepared for testing were $400 \mathrm{~mm}$ long, $50 \mathrm{~mm}$ wide and $50 \mathrm{~mm}$ high. Each beam was made up of two parts
TABLE 2 | Properties of tack coat materials

\begin{tabular}{llccc}
\hline Property & Unit & Type I & Type II & Type III \\
\hline Standard viscosity at $25^{\circ} \mathrm{C}$ & $\mathrm{S}$ & 12 & 19 & 16 \\
Evaporation residue content & $\%$ & 59 & 61 & 52 \\
Penetration degree $\left(100 \mathrm{~g}, 25^{\circ} \mathrm{C}, 5 \mathrm{~s}\right)$ & $0.1 \mathrm{~mm}$ & 90 & 55 & 70 \\
Ductility $\left(5^{\circ} \mathrm{C}\right)$ & $\mathrm{cm}$ & 41 & 86 & 75 \\
Softening point & ${ }^{\circ} \mathrm{C}$ & 62 & 98 & 78
\end{tabular}

and an interface joint in the middle. It should be noted that the preparation of the asphalt mixture followed the code (Code of China, 2011).

A customized steel mold with the dimension of $300 \times 400 \times$ $50 \mathrm{~mm}^{3}$ was used to prepare the asphalt mixture. Firstly, a loose mixture $\left(160^{\circ} \mathrm{C}\right)$ was laid in one-half of the mold and then uniformly distributed. Subsequently, a roller compactor was employed to compact the mixture in $2 \mathrm{~min}$ with vibrations so that the mixture reached its maximum density with a target air void content of $3.5 \%$. Then, the compacted mixture was left to cool down to the room temperature for 1 day.

The asphalt materials used as a tack coat were the ordinary emulsified asphalt, the highly viscous modified emulsified asphalt and the resin emulsified asphalt. Moreover, the tack coats were heated up to the specified application temperature. Then, every tack coat was uniformly applied on the cleaned surface with 0.3 , 0.6 and $0.9 \mathrm{~kg} / \mathrm{m}^{2}$, respectively. Subsequently, the coated surface was left at room temperature for $2 \mathrm{~h}$ to allow the curing procedure to complete. Following the tack coat application and its curing, the second half of the mold was filled with the loose mixture and compacted using a similar method applied in the first half. The slab was allowed to cool down at room temperature before conducting the cutting operation. In the final step, each slab was then cut into six beams with the dimension of $50 \times 50 \times$ $400 \mathrm{~mm}^{3}$ to prepare for the laboratory tests. Figure 1 illustrates the procedures of fabrication of the specimens in the laboratory.

In this study, various interface joint patterns were considered by changing the auxiliary movable steel plate used in the middle of the steel mold, as shown in Table 3. The composite beam sections with different interface patterns are shown in Figure 2.

\section{Pull-Out Test}

The pull-out test device (shown in Figure 3A) is used to evaluate the bonding strength of the interface joint of the beam-shaped specimens and to study the ability of the interface joint of the repaired potholed to withstand direct tension. During the pullout test, the two ends of the specimen were bonded to the mold by an epoxy resin, as shown in Figure 3B, and then the tensile force was applied to the specimen by top tension, as shown in Figure 3C.

The measured data from fatigue and the pull-out test results were automatically acquired and calculated by a data acquisition system.

\section{Fatigue Test}

A four-point bending test was implemented in the evaluation of the flexural fatigue performance of interface joint 
A

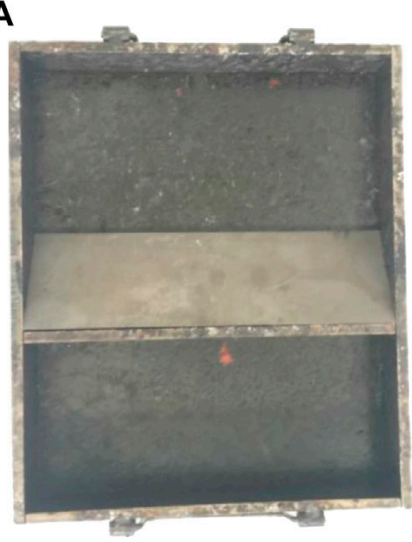

B

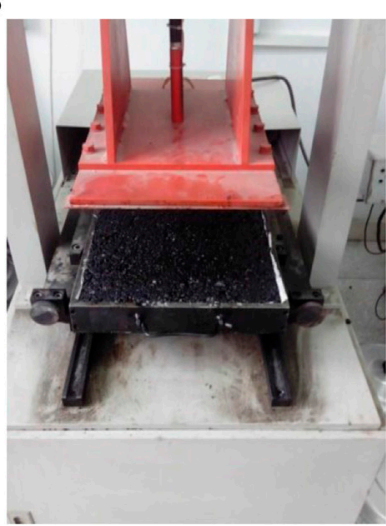

C

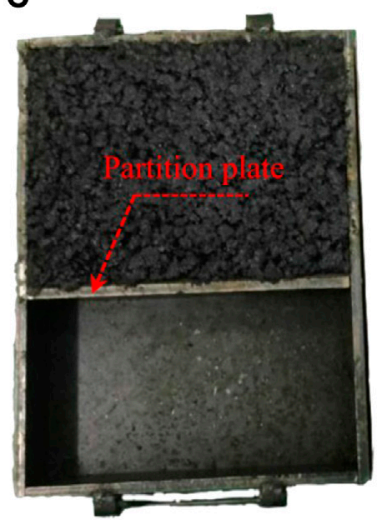

D

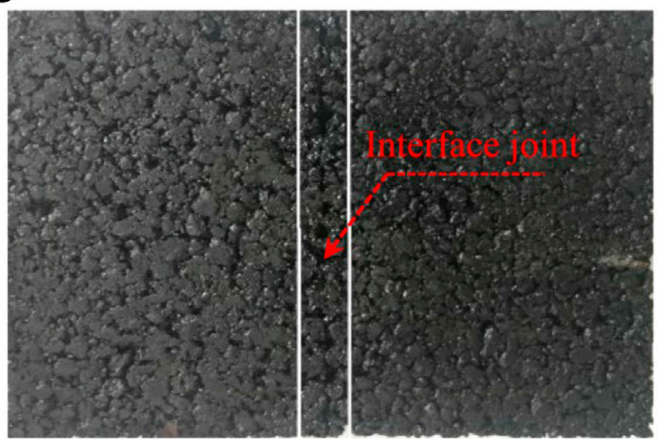

$\mathbf{E}$

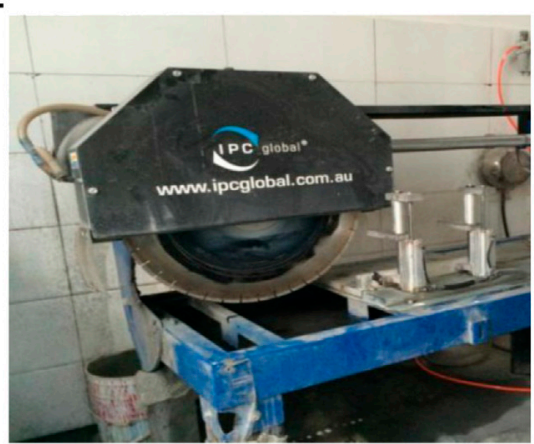

FIGURE 1 | The procedure of specimen fabrication: (A) steel mold with dividing plate; (B) mixture compaction; (C) half slab formation; (D) the whole slab formation; (E) specimen cutting.

in beam-shaped specimens to determine the service lives of the repaired interface joints in pothole patches under repeated loading conditions. The apparatus, the fatigue loading mechanism, and the schematic diagram of loading and stress distribution are shown in Figure $4 \mathrm{~A}, \mathbf{B}, \mathbf{C}$, respectively.

\section{EFFECT OF INTERNAL FACTORS ON INTERFACE JOINT PERFORMANCE}

\section{Test Plan (Phase I)}

It is important to guarantee the construction quality in the repaired potholes. The main factors affecting the pothole

TABLE 3 | Auxiliary movable steel plate with different bonding surface forms.

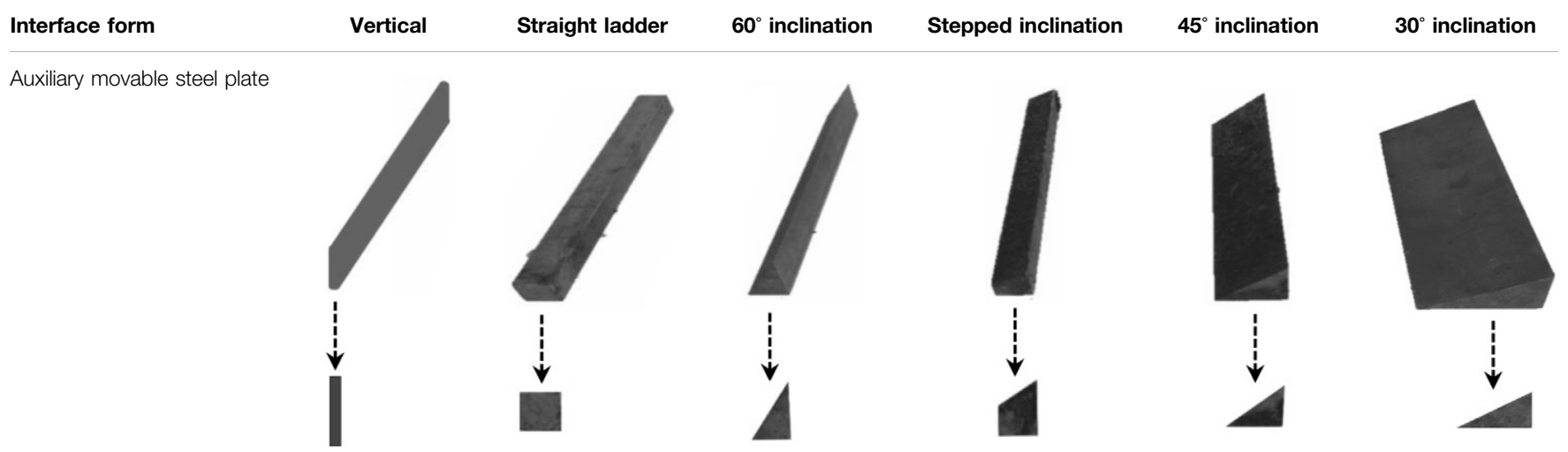



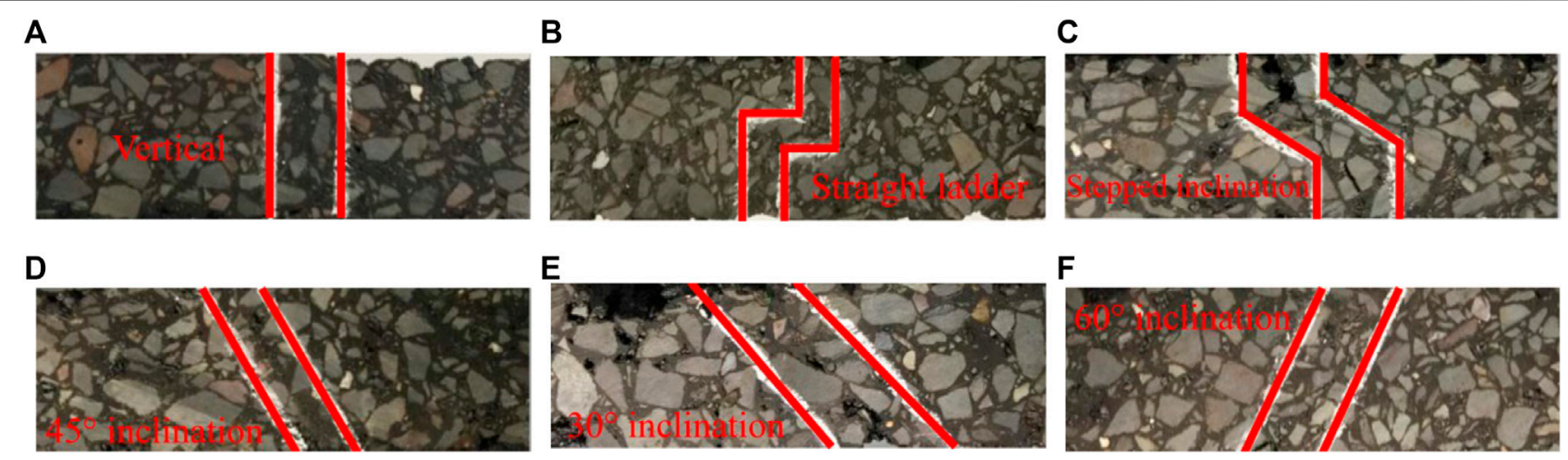

FIGURE 2 | Composite beam sections with different interface forms: (A) Type A; (B) Type B; (C) Type C; (D) Type D; (E) Type E; (F) Type F.

patching are the type and dosage of tack coat, and the form of the interface joint. The above factors can also interact and influence each other. Moreover, the effects of the three main factors on the properties of the new and old bond interfaces in pothole patches were studied. Three options were considered for the types of adhesive material and its application rate and six options were considered for the form of bonding surface (Table 4).

To facilitate the orthogonal analyses based on Table 4 and to improve test accuracy, the factors and corresponding levels were converted into three factors and three levels. The test scheme was designed based on the orthogonal tests and 18 test cases were obtained as shown in Table 5, respectively.

A previous study (Wang et al., 2002) showed that the most unfavorable temperature for fatigue failure of asphalt mixtures was within the range of $13-15^{\circ} \mathrm{C}$. In this study, $15^{\circ} \mathrm{C}$ was selected as the test temperature and $750 \mu \varepsilon$ was considered as the strain level in the four-point bending test. Besides, the pull-out test was also conducted at $15^{\circ} \mathrm{C}$.

\section{Determination of Optimal Bonding Condition of Interface Joint}

For each test case, three replications were considered, and the average values were calculated and presented. The test results are listed in Table 6.

The influence of factors $\mathrm{A}, \mathrm{B}$ and $\mathrm{C}$ on the fatigue life and bond strength of the composite beam was analyzed by orthogonal tests. The results of the horizontal value analysis of each factor are shown in Figure 5.

The following findings were observed:

(1) The most influencing factor on the fatigue life of the composite beam was the form of bonded surface. The fatigue life of the composite beam with $30^{\circ}$ inclination interface joint was 5.54 times higher than that with a vertical interface joint. In addition to the bonding interface form, the type and dosage of bonding materials imposed an insignificant effect on the fatigue life of
A

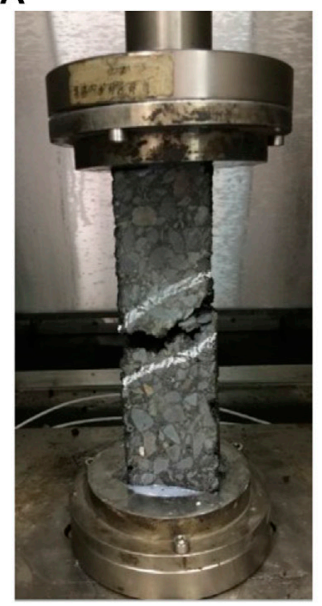

B

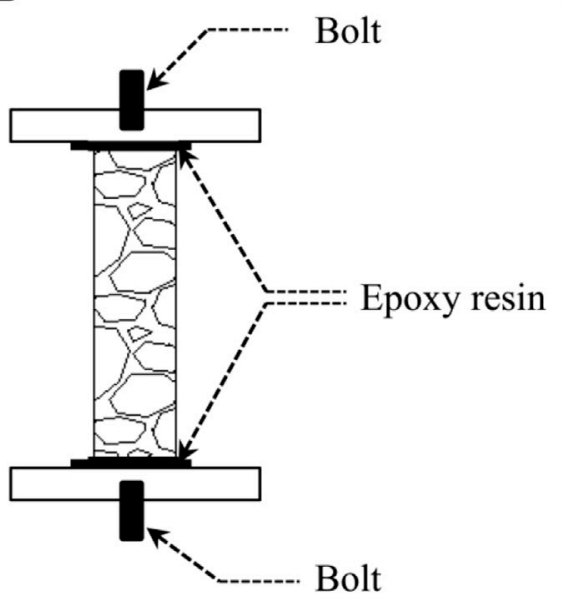

C

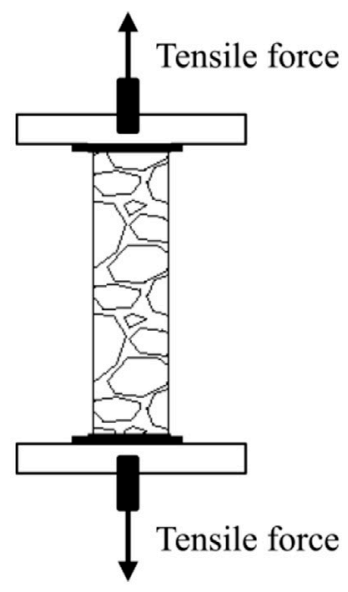

FIGURE 3 | Pull-out test equipment and schematic diagram of loading: (A) pull-out test setup; (B) specimen condition; (C) schematic diagram of loading. 
TABLE 4 | Experimental variables and the levels for internal conditions.

\begin{tabular}{|c|c|c|c|c|c|c|}
\hline \multirow[t]{2}{*}{ Variable } & \multicolumn{6}{|c|}{ Factor level (FL) } \\
\hline & 1 & 2 & 3 & 4 & 5 & 6 \\
\hline Binder type $(A)$ & Type I & Type ॥ & Type III & - & - & - \\
\hline Binder dosage $(\mathrm{B}) /\left(\mathrm{kg} / \mathrm{m}^{2}\right)$ & 0.3 & 0.6 & 0.9 & - & - & - \\
\hline Interface form (C) & Type A & Type B & Type C & Type D & Type E & Type F \\
\hline
\end{tabular}

composite beams. Consequently, in order to obtain the maximum fatigue life of the new and old interface bonding joints of the asphalt pavement, it is particularly important to consider the appropriate pavement cutting surface method.

(2) The most important factor affecting the bond strength of the composite beam is the type of tack coat material. In this regard, the highly viscous modified emulsified asphalt outperforms other types while the ordinary emulsified bitumen showed considerably lower performance. The bond strength of the composite beam with high viscoelastic modified emulsified asphalt as binder was 1.64 times higher than that with ordinary emulsified asphalt.

(3) In order to improve the fatigue life and bond strength of the composite beam, the highly viscous modified emulsified asphalt can be used as the best tack coat type. Moreover, the optimum binder dosage was $0.6 \mathrm{~kg} / \mathrm{m}^{2}$ and the appropriate cutting surface method among different surface types was $30^{\circ}$ inclination for obtaining the optimum fatigue life and bond strength of composite beams.

Therefore, it can be concluded that in order to improve the overall performance of pothole patches with interface joint, the best combination is using $30^{\circ}$ inclination as the cutting surface form, and executing bonding treatment with the high-viscous modified emulsified asphalt with an application rate of $0.6 \mathrm{~kg} / \mathrm{m}^{2}$.

\section{Effect of Interface Bond Joint on Pavement Performance}

Although the results of the above-mentioned orthogonal tests can be used for obtaining the optimal bonding condition for the new and old interface bonding joints of the pothole patches, to clarify the difference between the performances of the pavement before and after repair of pothole needs further research. In order to do this, various testing cases were conducted, as presented in Table 7, and their corresponding results are presented.

According to Table 7, it is obvious that the fatigue life of the composite beam is very low without treatment of the bonding surface (i.e., case 1). Considering the optimum condition for the bonding surface of the composite beam (i.e., case 2), the fatigue life of the composite beam was increased by 473 times. However, the specimen with the optimum bonding surface condition had only $11.3 \%$ of the fatigue life of the joint-less beam (i.e., case 3 ).

It can be concluded that although using the optimum bonding surface condition in pothole patches can considerably improve the fatigue life of the repaired pavement, the existence of the joints reduced the overall fatigue life of the pavement compared with

\begin{tabular}{|c|c|c|c|}
\hline \multirow[t]{2}{*}{ Test number } & \multicolumn{3}{|c|}{ Variable } \\
\hline & $\begin{array}{l}\text { Binder type } \\
\text { (A) }\end{array}$ & $\begin{array}{l}\text { Binder dosage } \\
\text { (B)/(kg/m²) }\end{array}$ & Interface form (C) \\
\hline 1 & Type I & 0.3 & Type A \\
\hline 2 & Type I & 0.6 & Type B \\
\hline 3 & Type I & 0.9 & Type D \\
\hline 4 & Type ॥ & 0.3 & Type B \\
\hline 5 & Type ॥ & 0.6 & Type D \\
\hline 6 & Type ॥ & 0.9 & Type A \\
\hline 7 & Type III & 0.3 & Type D \\
\hline 8 & Type III & 0.6 & Type A \\
\hline 9 & Type III & 0.9 & Type B \\
\hline 10 & Type I & 0.3 & Type C \\
\hline 11 & Type I & 0.6 & Type E \\
\hline 12 & Type I & 0.9 & Type F \\
\hline 13 & Type ॥ & 0.3 & Type E \\
\hline 14 & Type ॥ & 0.6 & Type F \\
\hline 15 & Type ॥ & 0.9 & Type C \\
\hline 16 & Type III & 0.3 & Type F \\
\hline 17 & Type III & 0.6 & Type C \\
\hline 18 & Type III & 0.9 & Type E \\
\hline
\end{tabular}

the undamaged one. Therefore, for the repaired pothole, the interface bonding joint can easily reduce the fatigue life and performance of the damaged asphalt pavement.

\section{FATIGUE PERFORMANCE OF INTERFACE JOINTS UNDER EXTERNAL FACTORS}

\section{Test Plan (Phase II)}

Using the determined optimum bonding condition, the fourpoint bending fatigue tests were carried out on the composite beams under different test temperatures, load frequencies and strain levels. In the fatigue test of four-point bending beam, the change in test frequency represents the change in load acting time on the beam specimen. The loading time reflects the driving speed in asphalt pavement. Thus, different test frequencies represent vehicles with different driving speeds. The load frequencies were selected as 2,10 and $15 \mathrm{~Hz}$ according to Eq. 1 (Mollenhauer et al., 2009), simulating the low speed of $8 \mathrm{~km} / \mathrm{h}$, the medium speed of $45 \mathrm{~km} / \mathrm{h}$, and the high speed of $70 \mathrm{~km} / \mathrm{h}$, respectively. In the fatigue test of four-point bending beam, the strain level reflects the deformation degree of the beam specimen, representing the load on the asphalt pavement. The strain levels used in the experimental tests were considered in a reasonable range. The strain levels of $750 \mu \varepsilon, 1,000 \mu \varepsilon, 1,250 \mu \varepsilon$, and $1,500 \mu \varepsilon$ were 


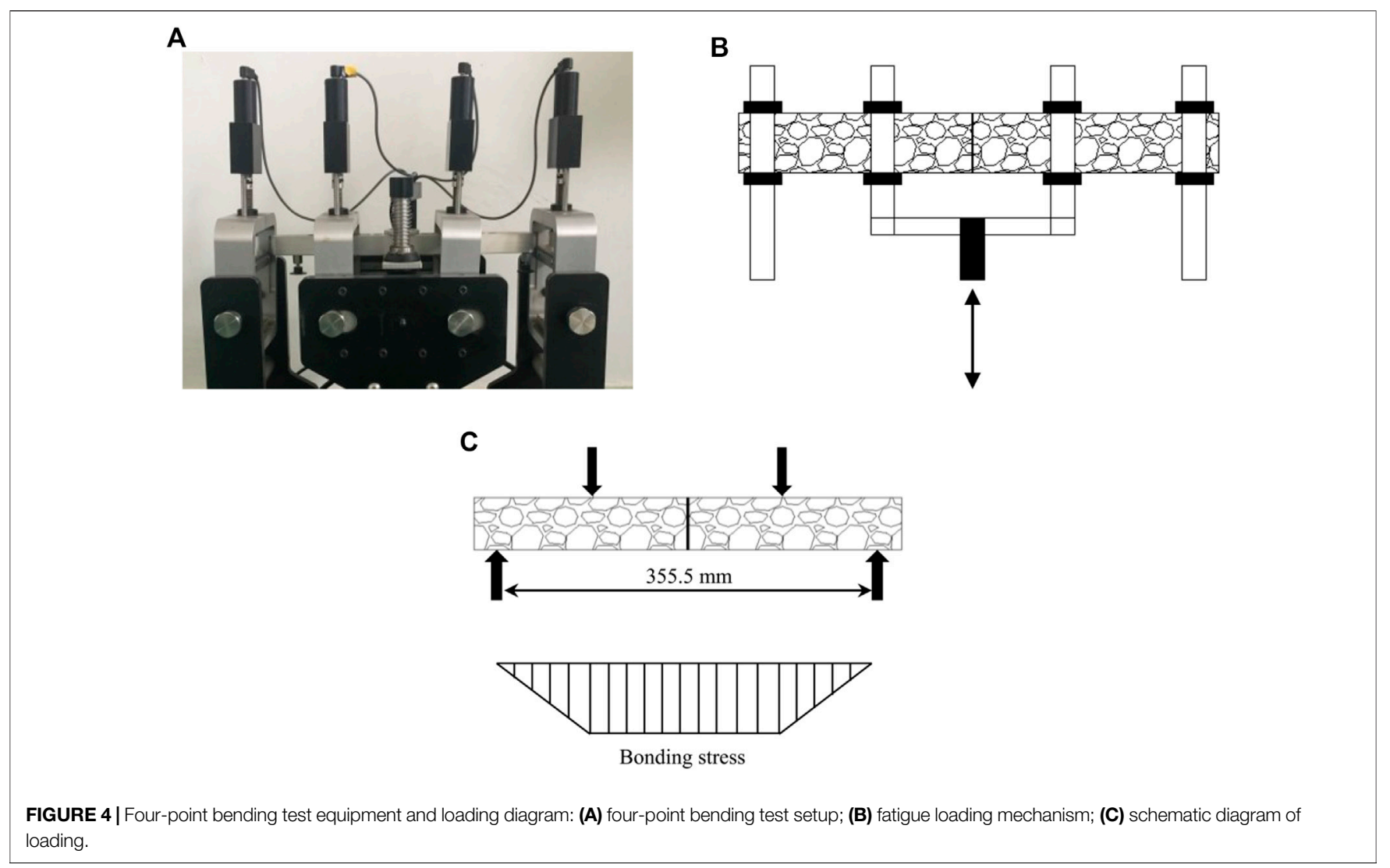

chosen to simulate four vehicle loads of small, relatively small, relatively large and large, respectively, acting on the pavement surface. Because the emulsified asphalt is usually used at normal temperature, the test temperature levels used in the experimental tests were $5,10,15$ and $25^{\circ} \mathrm{C}$, respectively.

$$
f=0.277 v^{0.944} \text {, }
$$

where $f$ is the load frequencies, $\mathrm{Hz}$; the $U$ is the speed, $\mathrm{km} / \mathrm{h}$.

\section{Effect of Strain Level}

Figure $\mathbf{6}$ shows the fatigue life against the strain level for different loading frequencies of 2,10 , and $15 \mathrm{~Hz}$, and different temperatures. It can be seen from Figure $\mathbf{6}$ that the fatigue life decreases by increasing the strain level. Moreover, different decreasing trends and shapes of logarithmic regression curves seen in Figure 6 at each frequency or temperature indicate that the fatigue life of the interface joint in the repaired potholes is significantly dependent on vehicle speed and temperature. At the same frequency, the higher the temperature and the greater the strain level, the lower the fatigue life of the pothole. This indicates that at the same speed, the truck can be considered as a more severe threat to the pothole patching on the asphalt pavement due to its heavyweight. Furthermore, as the temperature increased, the pothole repair life of the asphalt pavement was sharply reduced.

\section{Effect of Temperature}

In order to assess the influence of temperature on the fatigue life of interface joints, changing trend of fatigue life as a regression curve under different strain levels and load frequencies is illustrated in Figure 7. It can be observed that the higher the temperature is, the lower the fatigue life of the interface joint is

TABLE 6 | Fatigue life and bond strength of composite beams.

\begin{tabular}{|c|c|c|c|c|c|c|c|c|c|}
\hline Test number & 1 & 2 & 3 & 4 & 5 & 6 & 7 & 8 & 9 \\
\hline Fatigue life, $N_{f}$ (cycles) & 775 & 3,522 & 7,112 & 23,062 & 38,369 & 11,213 & 13,854 & 18,696 & 21,658 \\
\hline Bond strength (MPa) & 0.217 & 0.440 & 0.749 & 1.233 & 1.037 & 0.685 & 0.902 & 1.322 & 0.918 \\
\hline Test number & 10 & 11 & 12 & 13 & 14 & 15 & 16 & 17 & 18 \\
\hline Fatigue life, $\mathrm{N}_{\mathrm{f}}$ (cycles) & 58,698 & 62,577 & 55,365 & 79,849 & 69,598 & 34,671 & 21,495 & 35,694 & 27,584 \\
\hline Bond strength (MPa) & 1.020 & 1.008 & 0.892 & 1.330 & 1.356 & 1.463 & 0.714 & 0.775 & 1.076 \\
\hline
\end{tabular}




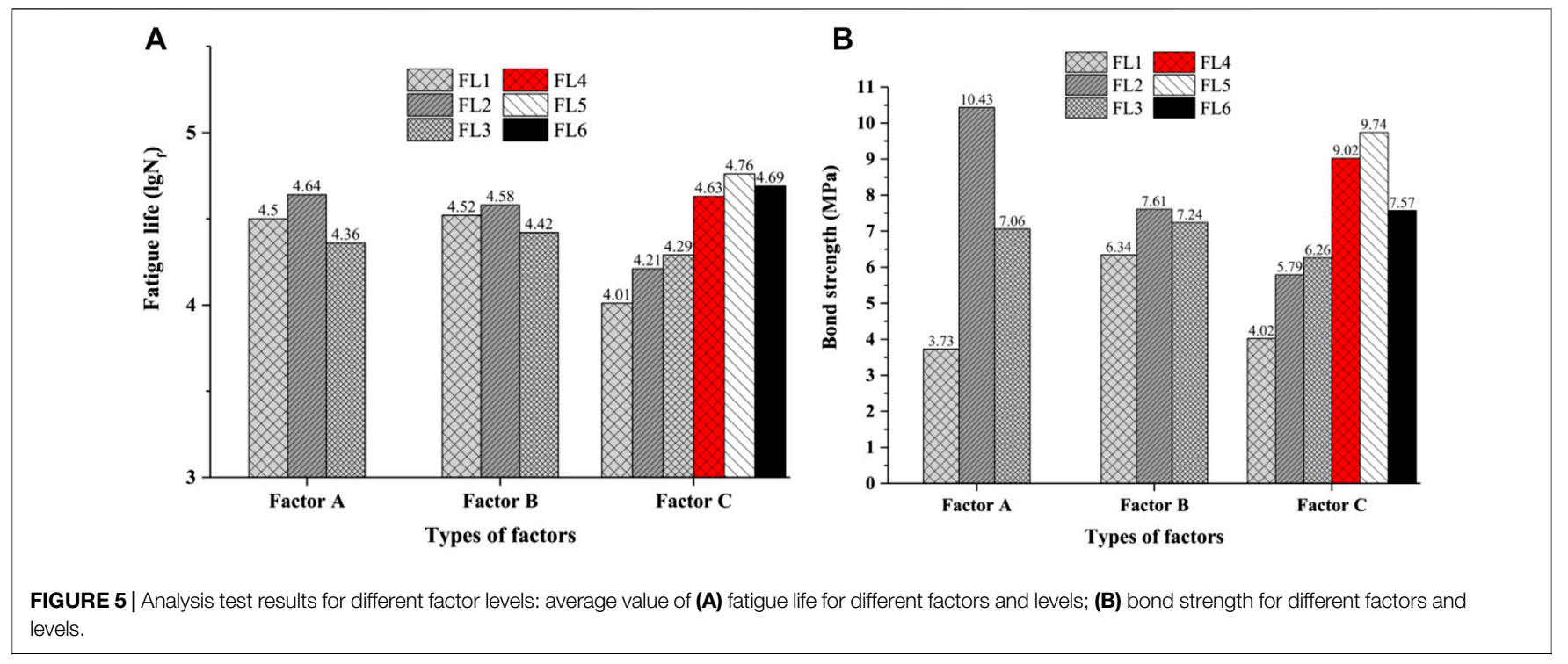

for different loading frequencies. Once the temperature reached a certain value, the adhesion of the interface joint was considerably declined, leading to the failure of the interface joint. When the repaired pavement was located in a high- temperature area, a tack coat with high-temperature resistance should be employed during the construction process, otherwise it may easily result in secondary damage of the repaired pothole.
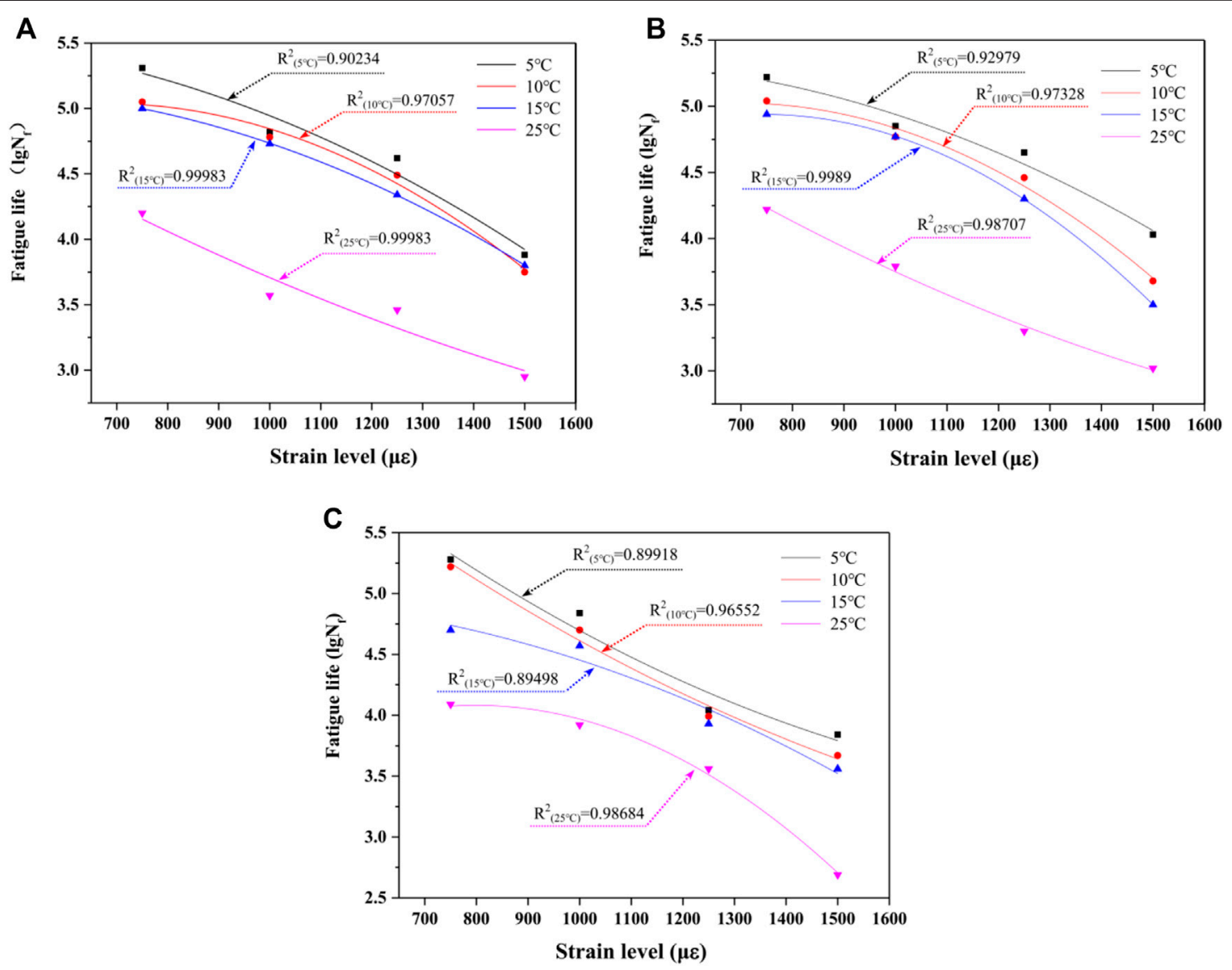

FIGURE 6 | Effect of strain on the fatigue life: (A) $2 \mathrm{~Hz}$; (B) $10 \mathrm{~Hz}$; (C) $15 \mathrm{~Hz}$. 
TABLE 7 | The different performances of the pavement before and after repair of pothole.

\begin{tabular}{|c|c|c|c|c|}
\hline \multirow[b]{2}{*}{ Study case } & \multicolumn{2}{|c|}{ Test design } & \multicolumn{2}{|c|}{ Test results } \\
\hline & Bonding joint condition & Simulation case in the field & Fatigue life, $\mathbf{N}_{\mathrm{f}}$ (cycles) & Bond strength (MPa) \\
\hline Case 1 & Vertical joint without tack coat & Routine repair of pavement & 205 & 0.0224 \\
\hline Case 2 & Bonding joint with optimal condition & Improved repaired pavement & 96,896 & 1.79 \\
\hline Case 3 & Joint-less & Ordinary joint-less pavement & 856,936 & 3.85 \\
\hline
\end{tabular}

The results of studying the influence of temperature and strain level on fatigue life indicated that the average fatigue life of the optimal potholes repair condition can reach 780 cycles at a relatively high temperature of $25^{\circ} \mathrm{C}$ and a relatively large strain level of $1,500 \mu \varepsilon$ that was 3.8 times of the traditional potholes repair (i.e., vertical joint form and no tack coat) at $15^{\circ} \mathrm{C}$ and $750 \mu \varepsilon$. The fatigue life of the best patching condition with an average value of 77,625 cycles in the temperature of $15^{\circ} \mathrm{C}$ and the strain level of $750 \mu \varepsilon$ was 379 times that of the traditional potholes repair (i.e., vertical joint form and no tack coat) under the same condition. Therefore, obtaining the best pothole repair scheme of asphalt pavement is feasible with excellent performance.

\section{Effect of Loading Frequency}

The effect of loading frequency on the fatigue life of the interface joint is presented in Figure 8. It can be seen that the maximum fatigue life was obtained at the frequency of $2 \mathrm{~Hz}$ followed by 10 and $15 \mathrm{~Hz}$. It can be concluded that the interface joint under the same treatment condition has a longer service life if it is located in the low-speed driving area. On the contrary, if the interface joint

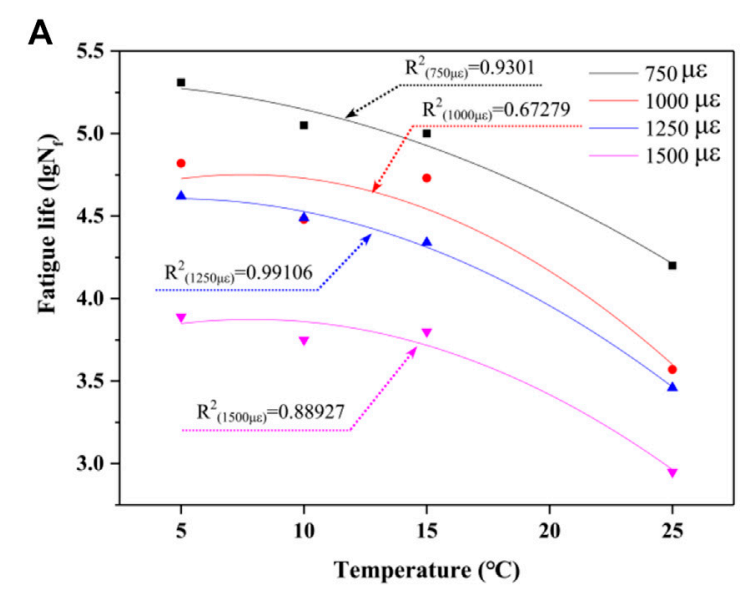

$2 \mathrm{~Hz}$

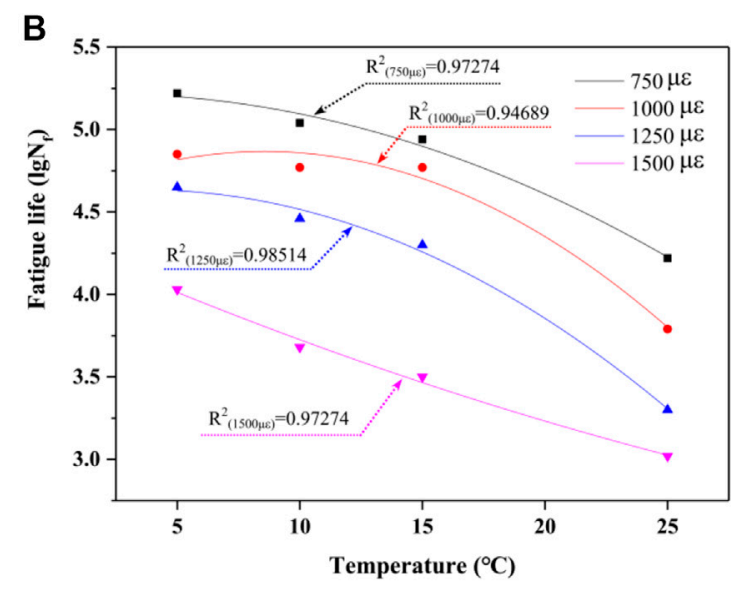

$10 \mathrm{~Hz}$

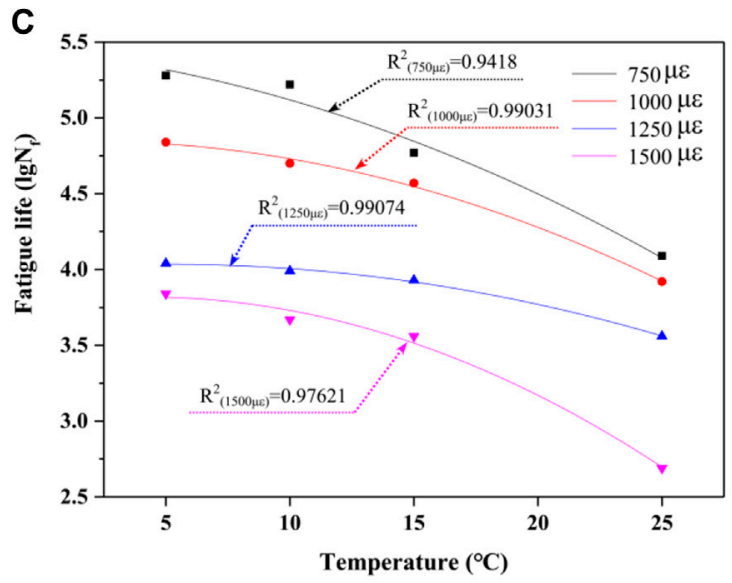

$15 \mathrm{~Hz}$

FIGURE 7 | Effect of temperature on the fatigue life: (A) $2 \mathrm{~Hz}$; (B) $10 \mathrm{~Hz}$; (C) $15 \mathrm{~Hz}$. 


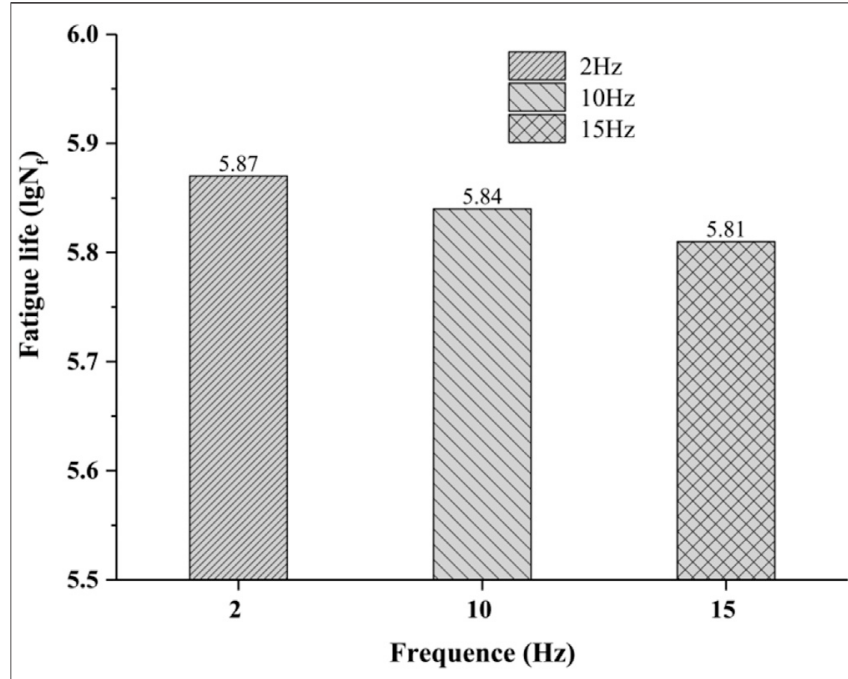

FIGURE 8 | Effect of loading frequency on the fatigue life.

is located in the high-speed driving area, it is more likely to be damaged and the corresponding service life is shorter.

\section{Prediction Model of Fatigue Life}

In order to predict the fatigue life of the repaired interface joints under the combined effect of various external factors, a multiple nonlinear regression model was established to predict the fatigue life $\left(\lg N_{f}\right)$ as a function of temperature $(T)$, frequency $(Z)$ and strain level $(H)$. The model is expressed in Eq. 2.

$$
\begin{aligned}
\lg N_{f}= & 17.68+0.0183 T-0.0017 T^{2}+0.0173 Z-0.0023 Z^{2} \\
& -1.87 \ln H .
\end{aligned}
$$

The correlation coefficient $\left(R^{2}\right)$ of the model is 0.931 , indicating that the accuracy of the developed model is high. To further verify the accuracy of Eq. 2, some measured data were randomly chosen, and the resulting percentage errors were calculated, as presented in Table 8.

Table 8 shows that the percentage error between the measured and the predicted fatigue life is small, and that can further prove that the proposed model has high reliability in predicting the fatigue life of interface joints.

\section{CONCLUSION}

In this study, the bond strength and fatigue life of different forms of interface joints for asphalt pavement pothole repair were studied under different experimental conditions, and the following conclusions are drawn:

This study investigate the influences of the joint surfaces of the pothole repairs and the types and dosage of tack coat materials on the bond strength and fatigue performance of the asphalt pavement potholes repair process through pullout and four-point bending tests. The results showed that the repaired pothole with an inclined surface has a much higher bond strength between the existing pavement and the repaired pothole compared to the conventional vertical pothole repair surface. The pothole repaired with a $30^{\circ}$ inclined surface and employing a high viscoelastic emulsified asphalt with a dosage of $0.6 \mathrm{~kg} / \mathrm{m}^{2}$ asphalt showed the highest bond strength amongst the investigated test conditions. The bond strength of this repaired pothole was 1.64 and 473 times of those with vertical joint potholes repair (vertical joint form and ordinary emulsified asphalt) and the traditional potholes repair (vertical joint form and without tack coat), respectively. Moreover, the fatigue life of the pothole repaired with a $30^{\circ}$ inclined surface and a high viscoelastic emulsified asphalt with a dosage of $0.6 \mathrm{~kg} / \mathrm{m}^{2}$ asphalt was 5.54 and 80 times of those with vertical joint pothole repair (vertical joint form and ordinary emulsified asphalt) and the traditional potholes repair (vertical joint form without tack coat), respectively. Therefore, the optimum pothole repair was found for $30^{\circ}$ inclination joint surface and high viscous modified emulsified asphalt with a dosage of $0.6 \mathrm{~kg} / \mathrm{m}^{2}$.

Moreover, the performance of the recommended optimum condition of pothole repair was further investigated at various temperature levels of $5,10,15$, and $25^{\circ} \mathrm{C}$, the strain levels of $750 \mu \varepsilon, 1,000 \mu \varepsilon, 1,250 \mu \varepsilon$, and $1,500 \mu \varepsilon$ and the loading frequencies of 2,5 , and $10 \mathrm{~Hz}$. The experimental investigation on the influence of temperature and strain levels revealed that the fatigue life of the optimum pothole repair was an average of 780 cycles at a relatively high temperature of $25^{\circ} \mathrm{C}$ and a relatively large strain level of $1,500 \mu \varepsilon$. Moreover, the fatigue life of the recommended optimum patching solution at the temperature of $15^{\circ} \mathrm{C}$ and the strain level of $750 \mu \varepsilon$ was averagely obtained as 77,625 cycles

\begin{tabular}{|c|c|c|c|c|}
\hline Number & Case & $\begin{array}{c}\text { Measured } \\
\text { fatigue life }\left(\operatorname{lgN}_{\mathbf{f}}\right)\end{array}$ & $\begin{array}{l}\text { Calculated fatigue life } \\
\qquad\left(\operatorname{lgN}_{\mathbf{f}}\right)\end{array}$ & Error (\%) \\
\hline 1 & $2 \mathrm{~Hz}, 5^{\circ} \mathrm{C}, 750 \mu \varepsilon$ & 5.31 & 5.37 & 1.13 \\
\hline 2 & $2 \mathrm{~Hz}, 10^{\circ} \mathrm{C}, 1,000 \mu \varepsilon$ & 4.78 & 4.80 & 0.42 \\
\hline 3 & $2 \mathrm{~Hz}, 15^{\circ} \mathrm{C}, 1,250 \mu \varepsilon$ & 4.34 & 4.26 & -1.84 \\
\hline 4 & $10 \mathrm{~Hz}, 10^{\circ} \mathrm{C}, 1,000 \mu \varepsilon$ & 4.77 & 4.72 & -1.05 \\
\hline 5 & $10 \mathrm{~Hz}, 15^{\circ} \mathrm{C}, 1,250 \mu \varepsilon$ & 4.3 & 4.12 & -4.19 \\
\hline 6 & $10 \mathrm{~Hz}, 25^{\circ} \mathrm{C}, 1,500 \mu \varepsilon$ & 3.02 & 3.34 & 10.60 \\
\hline 7 & $15 \mathrm{~Hz}, 15^{\circ} \mathrm{C}, 1,250 \mu \varepsilon$ & 3.93 & 3.97 & 1.02 \\
\hline 8 & $15 \mathrm{~Hz}, 25^{\circ} \mathrm{C}, 750 \mu \varepsilon$ & 4.09 & 4.43 & 8.31 \\
\hline 9 & $15 \mathrm{~Hz}, 5^{\circ} \mathrm{C}, 1,000 \mu \varepsilon$ & 4.84 & 4.99 & 3.10 \\
\hline
\end{tabular}

TABLE 8 | Comparison between the measured and predicted values of fatigue life. 
that was 379 times higher than the traditional pothole repair (vertical joint form without tack coat) under the same condition. Therefore, the recommended pothole repair condition of asphalt pavement showed excellent performance and was suitable for being employed at various temperature and loading conditions.

Based on the measured bond strength and fatigue life of the pothole repairs, a multivariate nonlinear regression model of fatigue life was developed for predicting the fatigue life of pothole repairs of asphalt pavements. The correlation coefficient of the regression model was $R^{2}=0.931$. By comparing the predicted values of the fatigue life regression model with the measured values, it was found that the error percentage was low. So, the model can be used to predict the fatigue life of the recommended pothole repair of asphalt pavement under different conditions.

\section{REFERENCES}

Code of China (2011). Standard test methods of bitumen and bituminous mixtures for highway engineering. Adyar, Chennai: People Transportation Press.

Ding, Z., Li, Y., Hou, J., Song, J., and Geng, J. (2016). Application of modified resin cold mixing mixture in pavement pothole repair. J. China Foreign Highway. 36 (6), 212-214. doi:10.14048/j.issn.1671-2579.2016.06.048

Dong, Q., Dong, C., and Huang, B. (2015). Statistical analyses of field serviceability of throw-and-roll pothole patches. J. Transport. Eng. 141 (9), 04015017. doi:10. 1061/(ASCE)TE.1943-5436.0000786

Dong, Q., Huang, B., and Jia, X. (2014a). Long-term cost-effectiveness of asphalt pavement pothole patching methods. Transport. Res. Rec. 2431 (2431), 49-56. doi:10.3141/2431-07

Dong, Q., Huang, B., and Zhao, S. (2014b). Field and laboratory evaluation of winter season pavement pothole patching materials. Int. J. Pavement Eng. 15 (4), 279-289. doi:10.1080/10298436.2013.814772

Fragachan, J. M. (2008). Accelerated testing methodology for evaluating pavement patching materials. Master degree. Worcester, MA: Worcester Polytechnic Institute.

Galehouse, L. (1998). Innovative concepts for preventive maintenance. Transport. Res. Rec. 1627, 1-6. doi:10.3141/1627-01

Ghosh, D., Turos, M., Hartman, M., Milavitz, R., Le, J.-L., and Marasteanu, M. (2018). Pothole prevention and innovative repair. St. Paul, M: Minnesota Department of Transportation.

Jiang, Z. (2017). Analysis on the application of circular grooves in pothole repairing of asphalt pavement. J. Highway Transport. Res. Develop. Appl. Technol. 13 (12), 131-132.

Kang, J., and Sun, Z. (2003). Mechanism analyses of pothole repair in asphalt concrete pavement. Highway, 112-115.

Kwon, J. B., Kim, D., Rhee, S. K., and Kim, Y. R. (2018). Spray injection patching for pothole repair using 100 percent reclaimed asphalt pavement. Construct. Build. Mater. 166, 445-451. doi:10.1016/j.conbuildmat.2018.01.145

Lee, J., Moon, S. J., Im, J., and Yang, S. (2017). Evaluation of moisture susceptibility of asphalt mixtures using dynamic modulus. J. Test. Eval. 45 (4), 20150136. doi:10.1520/JTE20150136

Li, J., Liu, J., Zhang, W., Liu, G., and Dai, L. (2019). Investigation of thermal asphalt mastic and mixture to repair potholes. Construct. Build. Mater. 201, 286-294. doi:10.1016/j.conbuildmat.2018.12.153

Li, S., and Li, H. (2016). Repair technology for permanent asphalt pavement pothole based on microwave heating. Guangdong Highway Commun. 146 (5), 21-25. doi:10.3969/j.issn.1671-7619.2016.05.004

\section{DATA AVAILABILITY STATEMENT}

The raw data supporting the conclusions of this article will be made available by the authors, without undue reservation.

\section{AUTHOR CONTRIBUTIONS}

LL: original draft preparation, formal analysis; $\mathrm{YH}$ : investigation, data curation; ZS: investigation,

\section{FUNDING}

This work was supported by the National Natural Science Foundation of China (Grant Nos. 51608457, 51878574).

Li, Z. (2016). Research on fast durable bonding materials and repair technology of asphalt pavement potholes. Master degree. China: Xi'an University of Architecture and Technology.

Little, D. N., and Jones Iv, D. R. (2003). "Moisture Sensitivity of asphalt pavements-a national seminar," in Chemical and mechanical processes of moisture damage IN hot-mix asphalt pavements. College Station, Texas: Texas A\&M University.

Maher, A., Gucunski, N., Yanko, W., and Petsi, F. (2001). Report No.: 2001-02 Final Report. Evaluation oF pothole patching materials. Available at: https:// cait.rutgers.edu/wp-content/uploads/2018/05/fhwa-nj-2001-002.pdf

Mao, Q. (2004). Research on technology for pothole patching of asphalt concrete pavements. McLean, IL: U.S. Department of Transportation.

Mollenhauer, K., Wistuba, M., and Rabe, R. (2009). Loading Frequency and fatigue: in situ conditions \& impact on test results Braga of Portugal. Braga, Portugal: University of Minho.

Nicholls, C., Kubanek, C., Karcher, C., Hartmann, A., Adesiyun, A., Ipavec, A., et al. (2014). "Transport research arena conference: transport Solutions from Research to deployment," in Transport Research Arena (TRA) 5th conference: transport solutions from research to deployment. 14 April 2014, Paris, France.

Obaidi, H., Gomez-Meijide, B., and Garcia, A. (2017). A fast pothole repair method using asphalt tiles and induction heating. Construct. Build. Mater. 131, 592-599. doi:10.1016/j.conbuildmat.2016.11.099

Paige-Green, D. P., Maharai, A., Komba, J., and Stellenbosch (2010). Potholes: technical guide to their causes, identification and repair. South Africa: CSIR Built Environment.

Prowell, B., and Franklin, A. (1996). Evaluation of cold mixes for winter pothole repair. Transport. Res. Rec. J. Transport. Res. Board. 1529, 76-85. doi:10.1177/ 0361198196152900110

Shao, Z., Tao, J., Huang, Y., Ai, C., and Jiang, Y. (2019). Experiment on the influence of new and old asphalt pavement bonding interface treatment on pavement performance. J. China Foreign Highway. 39 (2), 33-37. doi:10.1177/ 0361198196152900110

Shi, N. (2006). Analysis on saw cut repair of rehabilitaing worn asphalt pavement. J. Chongqing Jiaotong Univ 25 (S1), 62-63-143. doi:10.3969/j.issn.1674-0696. 2006.z1.020

Tong, L. (2014). Research on the rapid repairing Material of asphalt pavement pothole. Master degree. Xi'an, China: Chang'an University.

Wang, P., Liu, C., and Zhao, F. (2013). A brief discussion on bituminous concrete pavement pit repair spray technology. Highways. 58 (12), 210-213.

Wang, X., Sha, A., and Xu, Z. (2002). Dynamic characteristics and dynamic parameters of asphalt pavement materials. Beijing: China Communications Press. 
Wang, Y. (2011). New emulsified asphalt mixture and repair technology. Master Degree. Xi'an, China: Chang'an University.

Wilson, T. P., and Romine, A. R. (2001). Materials and procedures for repair of potholes in asphalt-surfaced pavements-manual of practice. McLean, IL: U.S. Department of Transportation.

Yang, Y., Qian, Z., and Song, X. (2015). A pothole patching material for epoxy asphalt pavement on steel bridges: fatigue test and numerical analysis. Construct. Build. Mater. 94, 299-305. doi:10.1016/j.conbuildmat.2015.07.017

Yuan, Z. (2017). Problems that should be paid attention to in repairing asphalt pavement pothole with cold filling asphalt mixture. J. Highway Transport. Res. Develop. Appl. Technol. 13 (6), 117-118.
Conflict of Interest: The authors declare that the research was conducted in the absence of any commercial or financial relationships that could be construed as a potential conflict of interest.

Copyright (c) 2021 Li, Huang, Shao and Ren. This is an open-access article distributed under the terms of the Creative Commons Attribution License (CC $B Y$ ). The use, distribution or reproduction in other forums is permitted, provided the original author(s) and the copyright owner(s) are credited and that the original publication in this journal is cited, in accordance with accepted academic practice. No use, distribution or reproduction is permitted which does not comply with these terms. 